\title{
Innovation in the Public Sector: A Systematic Review and Future Research Agenda
}

\author{
Hanna de Vries ${ }^{1}$, Victor Bekkers ${ }^{2}$, Lars (L.G.) Tummers ${ }^{3}$
}

Final version for Public Administration

Address correspondence to the author at Devries@fsw.eur.nl

To be cited as: De Vries, H.A., Bekkers, V.J.J.M., L.G. Tummers (forthcoming). Innovation in the Public Sector: A Systematic Review and Future Research Agenda. Public Administration

1 Department of Public Administration, Erasmus University Rotterdam, The Netherlands, Devries@fsw.eur.nl

2 Department of Public Administration, Erasmus University Rotterdam, The Netherlands, Bekkers@fsw.eur.nl

${ }^{3}$ Department of Public Administration, Erasmus University Rotterdam, The Netherlands \& Center for the study of Law and Society, University of California, Berkeley, The United States, Tummers@fsw.eur.nl 


\begin{abstract}
This article brings together empirical academic research on public sector innovation. Via a systematic literature review we investigate 181 articles and books on public sector innovation, published between 1990 and 2014. These studies are analysed based on the following themes: (1) the definitions of innovation, (2) innovation types, (3) goals of innovation, (4) antecedents of innovation and (5) outcomes of innovation. Based upon this analysis, we develop an empiricallybased framework of potentially important antecedents and effects of public sector innovation. We propose three future research suggestions: (1) more variety in methods: moving from a qualitative dominance to using other methods, such as surveys, experiments and multi-method approaches; (2) emphasize theory development and testing as studies are often theory-poor; and (3) conduct more cross-national and cross-sectoral studies, linking for instance different governance and state traditions to the development and effects of public sector innovation.
\end{abstract}

\title{
Keywords:
}

- Systematic review

- Innovation

- Public sector

- Public entrepreneurship 


\section{Introduction}

Scholars and practitioners have become increasingly interested in innovation in the public sector (Osborne and Brown 2011; Walker 2014). Many embrace the idea that innovation can contribute to improving the quality of public services as well as to enhancing the problem-solving capacity of governmental organizations in dealing with societal challenges (Damanpour and Schneider 2009). Frequently, public sector innovation is linked to reform movements such as New Public Management (Pollitt and Bouckaert 2011), electronic government (Bekkers and Homburg 2005), the change from government to governance (Rhodes 1996) and, most recently, to the discussions on the retreating role of government in a 'Big Society' (Lowndes and Pratchett 2012).

In the private sector, innovation is an established field of study that tries to explain why and how innovation takes place (Fagerberg et al. 2005). General literature reviews and systematic reviews have been carried out to assess the state-of-the-art in this field as well as to generate new avenues for theory building and research (Perks and Roberts 2013). There are even some metaanalyses, such as that of Damanpour (1991), that pull together the results of empirical research on the relationships between organizational variables, such as slack resources, and innovation.

However, what is known about innovation in the public sector? What topics have been addressed in the innovation studies to date, and what are the possible avenues for future research? Moreover, what can be added to the current methodological state-of-the art when it comes to public innovation research?

The first contribution of this article is methodological in that we have elected to conduct a systematic review (Moher et al. 2009). These differ from traditional literature reviews in that they are replicable and transparent, involving several explicit steps such as using a standardized way to identify all the likely relevant publications. In public administration, such systematic reviews have become increasingly popular (e.g. Tummers et al. forthcoming). Nevertheless, a comprehensive systematic overview of public sector innovation is still lacking.

Second, most of the literature reviews on public innovation that have been conducted in recent years aim to conceptually, rather than empirically (for example, based on explicit data such as in case studies and surveys), grasp the meaning and importance of public sector 
innovation (examples are Osborne and Brown 2011; Sørensen and Torfing 2011). Others address this challenge through a normative approach (for instance, Bason 2010). This can be seen as a substantial shortcoming as systematic overviews of empirical evidence are essential to summarize the existing, evidence-based body of knowledge and to establish a future research agenda (e.g. Greenhalgh et al. 2004). As such, our investigation is able to identify areas where substantial progress has been made, and point to areas where future studies could best be directed.

A third related contribution concerns the antecedents in the innovation process. Given the predominance of conceptual or normative overviews, the question can be raised as to how much we currently know about the underling process of public sector innovation as mapped in the innovation studies. Do we really know the impeding and the stimulating antecedents?

In addressing this topic, we embed our research questions in the open innovation debate that stresses the content, course and outcome of the innovation process as the result of complex interactions between intra-organizational antecedents, resources and actors and external, environmental antecedents, resources and actors. This interaction presupposes rather open boundaries between an organization and the environmental context in which it operates, and can be understood in terms of drivers and barriers (Chesbrough 2003). Recently, such approaches can also be seen in research into public sector innovation (Osborne and Brown 2013, p. 7).

As a result of these porous boundaries, antecedents that need to be further explored in public innovation research include both the environmental and the organizational contexts in which innovations take place, their nature, and also the enabling antecedents and their underlying contingencies. Moreover, there is a need to look deeper into the goals and effects of the innovation process since, whilst innovation and improvement have often been assumed synonymous, this is by no means always the case (Osborne and Brown 2013, p. 4; see also Hartley 2005).

In response to these questions, this article provides a comprehensive overview of how public innovation has been studied by addressing (1) the definitions of innovation, (2) innovation types, (3) goals of innovation, (4) antecedents in the innovation process and (5) outcomes. This 
research design is aligned with other systematic reviews in the social science field such as that of Greenhalgh et al. (2004).

Based on this, our overall guiding research questions can be phrased as follows:

1. What definitions of public sector innovation are being used?

2. What public sector innovation types can be distinguished?

3. What are the goals of public sector innovation?

4. Which antecedents influence the public sector innovation process?

5. What are the outcomes of the public sector innovation process?

This brings us to the outline of this article. The next section describes the methodology used to conduct the review. When reporting, we will follow the 'Preferred Reporting Items for Systematic Reviews and Meta-Analyses' (PRISMA) approach (Moher et al. 2009, see Appendix). Then, Section 3, the 'Results of systematic review', presents the characteristics of the eligible studies found and provides answers to the research questions listed above. Based on these results, we draw conclusions in Section 4 and develop a future research agenda on innovation in the public sector in Section 5.

\section{Methodology}

\subsection{Literature search}

Four strategies were used to identify eligible studies (Cooper 2010). We selected the period from January 1990 to March 2014 to include two important publications published in the early 1990s, namely Hood (1991) and Osborne and Gaebler (1992). These provided strong inputs to the NPM debate, which in turn stimulated new ways of working in governmental organizations and resulted in growing attention being given to public sector innovation.

First, we carried out an electronic search in two databases, ISI Web of Knowledge and Scopus, to ensure we included a broad range of scientific output. We started with the search term 
[innovat*], and this search generated more than 9,000 studies and was last conducted in April 2014. We decided to also search on the term [entrepreneur*] as innovation is often connected to entrepreneurship. For instance, Joseph Schumpeter (1942), the founding father of modern innovation theory, defined innovation as a process of creative destruction in which new combinations of existing resources are achieved. He defines entrepreneurship as 'Die Durchsetzung neuer Kombinationen': that is, the will and ability to achieve new combinations that can compete with established combinations. Hence, entrepreneurship is inherently connected to innovation as this is all about the will and ability of individuals to achieve new combinations (Bekkers et al. 2011).

Second, we searched for journal articles on innovation published in five top public administration journals, as we wanted to cover how innovation was defined there. These journals were Governance, Journal of Public Administration Research and Theory, Policy Sciences, Public Administration and Public Administration Review. The last search was conducted in April 2014 and this generated 34 possible studies for inclusion. Additionally, we also added three non UK/USA oriented journals, Canadian Public Administration, International Review of Administrative Sciences and Chinese Public Administration Review, to minimize the risk of bias in the selection. This search generated 36 possible studies for inclusion.

Third, we sought relevant books using Google Books and similar information sources. This search was last conducted in April 2014 and generated 89 possible studies for inclusion.

Fourth, we contacted experts in the field of public innovation and asked them to check the list of eligible publications, and to indicate possible gaps. They identified 35 further studies. We received the last expert e-mail in April 2014.

Although we used four search strategies, we must acknowledge a potential limitation caused by the search criterion of seeking the terms innovation and entrepreneurship. As such, we were placing our work firmly within the public administration discipline. However, it is possible that we missed studies dedicated to innovation because different terminology, such as change, was used. Although adding more terms is potentially worthwhile (and 'change' might have thrown up more negative findings than 'innovation' which has positive overtones), this would 
have been extremely time consuming as we already had to scan around 10,000 article titles. Hence, we decided to limit ourselves to the search terms innovation and entrepreneurship (or derivatives thereof).

\subsection{Eligibility criteria}

In reporting the systematic review, we adhere to the widely used 'Preferred Reporting Items for Systematic Reviews and Meta-Analyses' (PRISMA, see Appendix). Studies from our original searches were included in the systematic review if they met all of the following inclusion criteria:

- Field - Studies should deal with innovation in the public sector. We defined the public sector as the "those parts of the economy that are either in state ownership or under contract to the state, plus those parts that are regulated or subsidized in the public context' (Flynn 2007, p. 2).

- Topic - Studies should contain the words innovat* or entrepreneur* in their title and/or abstract in order to prevent confusion with related concepts. For the first search term, it was not necessary for the word 'public' to be in the title or abstract since some studies are carried out in a specific public policy field (such as education) without mentioning the term 'public'. However when we searched for the term 'entrepreneur*', the word 'public' had to be included in the title or abstract as our review was focused on innovation in the public sector.

- Study design - Only empirical studies were eligible as we are interested in empirical evidence on public sector innovation. All research designs were allowable (e.g. questionnaire, case study, experiment) but case studies that were purely illustrative in nature were excluded. We also excluded systematic reviews (e.g. Greenhalgh et al. 2004) to avoid including studies twice.

- Year of publication - Studies were retrieved that were published in the period from January 1990 to March 2014.

- Language - Only studies written in English were considered. 
- Publication status - Only international peer-reviewed journal articles and books from well-established publishers in the field of public administration and innovation were included.

\subsection{Study selection}

In total, we screened around 10,000 studies. Based on the eligibility criteria, we eventually included 181 studies in our analysis. Our selection process is presented in Figure 1.

FIGURE 1 PRISMA flow diagram

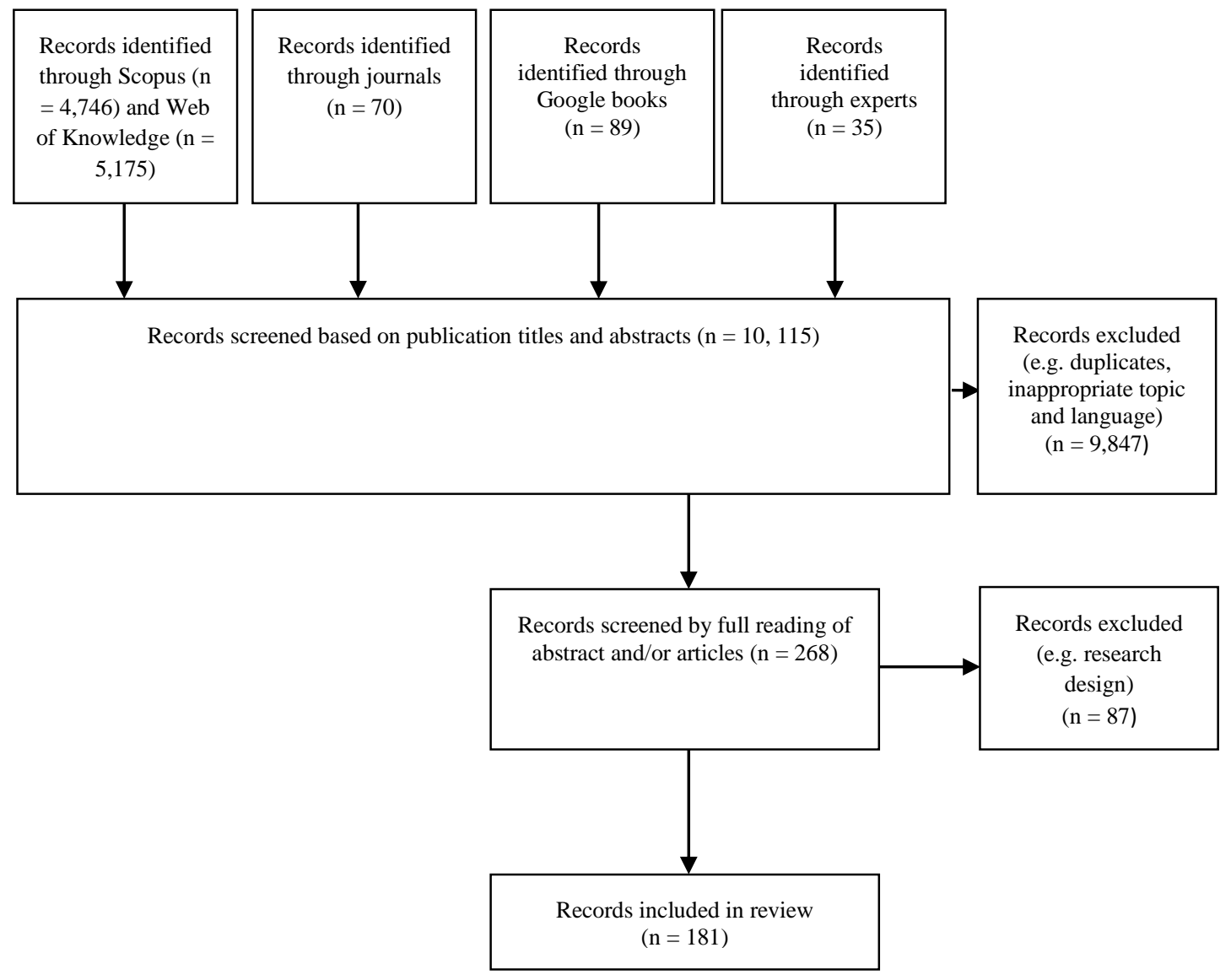

First, we screened the studies by scanning the abstracts and titles. Here we checked if all our inclusion criteria (e.g. topic, language and year) were met. For instance, one of our inclusion criteria was that the word innov* or entrepreneur* had to be included in the title and/or abstract.

For many studies this was not the case. We also found studies in other languages (e.g. Spanish or French) or not conducted in the public sector. In this step, we also removed duplicates. 
In the second step, we screened studies by reading the full abstracts and/or the full text. Here, we excluded further studies mainly because they were theoretical in nature or had a weak empirical design (such as case studies that were only illustrative in nature to support a theoretical argument, e.g. Moore and Hartley 2008). This was not always clear from the abstracts, requiring, in some cases, the full paper to be read.

For each empirical study, we developed a data extraction form to summarize the author(s), publication year, title, journals, methods used, definition used, innovation types applied, antecedents in the innovation process and outcomes. We then inductively divided the primary studies' findings on the antecedents into four broad categories that refer to four levels: (1) the environmental level, (2) the organizational level, (3) the innovation itself and (4) the individual level. Within each category of antecedents, we identified subtopics such as, on the organizational level, slack resources and leadership. These labels were frequently discussed among the researchers. A similar process was conducted to code the innovation types, goals and outcomes.

We acknowledge that such coding is inherently subjective, and that there are many connections between, for instance, the different types of antecedents. Nevertheless, we believe that the distinctions made can serve as a useful analytical tool to guide the extraction of findings on innovation.

The studies were independently coded by one of three researchers. To safeguard the quality of the review, the researchers discussed 'difficult' fragments by phone, Skype or in face-to-face meetings. In this process, new labels for antecedents, goals or outcomes were introduced and others deleted. Additionally, we also used CitNetExplorer, a new software tool that has been developed for analysing and visualizing direct citation networks (Van Eck and Waltman 2014), to see if they were any underlying patterns in the antecedents included. The main aim of this tool is to study the development of a research field over time as "by showing the most important publications in a field, ordered by the year in which they appeared, and the citation relations between these publications, one obtains a picture of the development of a field over time' ( $p$. 803). Since bibliographic data reflect the references that authors cite in scholarly publications, 
bibliometric maps can be said to represent the self-portrait of a scientific community that its members have unconsciously drawn over time.

In the next section we describe our findings.

\section{Results of systematic review}

\subsection{Journals and countries}

The articles included in the systematic review were published in 90 different journals. Many were published in Public Management Review (16), Public Administration (12), Public Administration Review (10) and the Journal of Public Administration Research and Theory (10). Besides these public administration journals, articles were also found in very specific and dedicated journals such as Health Care Management Review. When looking to the various book publishers, most of the books included were published by well-established publishers such as Palgrave Macmillan. The synthesized results of all the records identified show that the number of studies has increased rapidly in recent years: 61\% of all the selected studies were published between 2009 and 2014, the others between 1990 and 2009.

Many of the studies were conducted in the USA and in the UK (25\%, and 19\% respectively). This suggests that the American - Anglo-Saxon perspective is central when studying innovation, which could have important implications as there might be an institutional bias present. This might also influence the external validity of the findings, raising questions as to how applicable they might be in other western or non-western (e.g. China) settings. A further finding was that most of the studies included $(144 ; 80 \%)$ were conducted in a single country, indicating a lack of cross-country comparisons.

\subsection{Research methods}

Most of the studies analysed were qualitative in nature $(101 ; 56 \%)$, mainly adopting a multiple (50) or single case (21) study approach. Quantitative studies were less common (56; 31\%). Only a small group of studies $(24 ; 13 \%)$ were based on data that were both quantitative and qualitative in nature (for instance, Nählinder 2010). As such, a qualitative bias prevails. Given this approach, 
the context of innovation and the antecedents within this context have received substantial attention.

\subsection{Policy fields and government layers}

Given the broad sweep of our review of public sector innovation studies in general, we were interested in identifying the specific policy fields in which the innovations took place as well as the dominant layer of government. The largest group of innovation studies were conducted on the local government level $(58 ; 27 \%$, some studies included more than one policy field or government layer), followed by central government $(39 ; 18 \%)$ and healthcare $(30 ; 14 \%)$, with many of the latter being carried out in the UK (e.g. Turner et al. 2011). This significant presence of both healthcare and local government can be largely attributed to the UK Labour government's programme of supporting public management reform since this encouraged innovation studies. Only a few studies were conducted in the welfare $(17 ; 8 \%$, e.g. Brown 2010) or education subsectors (11; 6\%, e.g. Maranto and Wolf 2013). Some studies also referred to the public sector in general terms without identifying subsectors (e.g. Kumar and Rose 2012).

In the following sections, we provide the answers to our research questions: the definitions of innovation used (RQ1, Section 3.4), innovation types (RQ2, Section 3.5), goals (RQ3, Section 3.6), antecedents in the innovation process (RQ4, Section 3.7 for general and Section 3.8 for adoption/diffusion) and outcomes (RQ5, Section 3.9). Finally, in Section 3.10, we describe the relationships between innovation types and antecedents and between innovation types and outcomes.

\subsection{Definitions used}

In this section, we look at the various definitions applied in the studies. The most remarkable finding is that most articles do not provide a definition of innovation $(137 ; 76 \%)$. Often, the boundaries of the concept were not referred to; for instance because the main topic of the study was innovators rather than innovation itself (e.g. Meijer 2014). When innovation was defined, the 
definition was often quite general (44 of our sample (24\%) used a general definition). Most definitions were based on Rogers (2003, p. 12) who defines innovation as 'an idea, practice, or object that is perceived as new by an individual or other unit of adoption'. Also based on Rogers, various authors defined innovation as 'the adoption of an existing idea for the first time by a given organization' (e.g. Borins 2000). Twenty-seven studies defined a specific type of innovation (such as a product innovation).

When turning to the studies including a general definition, two main dimensions were stressed in the definitions used. First, the perceived novelty was mentioned in 37 of the 44 general definitions (e.g. Bhatti et al. 2011). Second, the first adoption of an idea by a given organization was also noted (five studies, e.g. Borins 2000). Seventeen studies included both elements (e.g. Salge and Vera 2012). Interestingly, only a few studies (e.g. Brown 2010) referred to the extent that a discontinuity with the past was present. This can be considered a substantial weakness since its inclusion offers the possibility to distinguish between innovation and incremental change. For instance, Osborne and Brown (2013, p. 3) argue how the distinctive nature and challenges of innovation, as opposed to 'continuous' change, can otherwise become lost as innovation can be considered a specific discontinuous form of change.

The next step is to look at the different innovation types included.

\subsection{Innovation types}

As the definition of innovation in the public sector is often quite broad, innovation types are often specified (Moore and Hartley 2008). Past research has argued that distinguishing types of innovation is necessary for understanding organizations' innovative behaviour because they have different characteristics and their adoptions are not affected identically by, for instance, organizational antecedents (Walker 2006).

Based on a review of the innovation literature, we have classified four innovation types as shown in Table 1. These types are sometimes defined as dimensions of innovation, particularly in the private sector literature (Damanpour 1991). We consider dimensions and types to both refer to the same phenomenon and indeed the terms are often used interchangeably. 
TABLE 1 Public sector innovation types applied

\begin{tabular}{|c|c|c|c|}
\hline Innovation type & Focus & References & Examples \\
\hline Process innovation & $\begin{array}{l}\text { Improvement of quality and } \\
\text { efficiency of internal and } \\
\text { external processes }\end{array}$ & Walker (2014) & \\
\hline $\begin{array}{l}\text { Administrative process } \\
\text { innovation }\end{array}$ & $\begin{array}{l}\text { Creation of new } \\
\text { organizational forms, the } \\
\text { introduction of new } \\
\text { management methods and } \\
\text { techniques and new } \\
\text { working methods }\end{array}$ & Meeus and Edquist (2006) & $\begin{array}{l}\text { Creation of a 'one-stop } \\
\text { shop' by a municipality, } \\
\text { where citizens can access } \\
\text { various services at a single } \\
\text { location }\end{array}$ \\
\hline $\begin{array}{l}\text { Technological process } \\
\text { innovation }\end{array}$ & $\begin{array}{l}\text { Creation or use of new } \\
\text { technologies, introduced in } \\
\text { an organization to render } \\
\text { services to users and } \\
\text { citizens }\end{array}$ & Edquist et al. (2001) & Digital assessment of taxes \\
\hline $\begin{array}{l}\text { Product or service } \\
\text { innovation }\end{array}$ & $\begin{array}{l}\text { Creation of new public } \\
\text { services or products }\end{array}$ & $\begin{array}{l}\text { Damanpour and Schneider } \\
\text { (2009) }\end{array}$ & $\begin{array}{l}\text { Creation of youth work } \\
\text { disability benefits }\end{array}$ \\
\hline Governance innovation & $\begin{array}{l}\text { Development of new forms } \\
\text { and processes to address } \\
\text { specific societal problems }\end{array}$ & Moore and Hartley (2008) & $\begin{array}{l}\text { Governance practice that } \\
\text { attempts to enhance the } \\
\text { self-regulating and self- } \\
\text { organizing capacities of } \\
\text { policy networks }\end{array}$ \\
\hline Conceptual innovation & $\begin{array}{l}\text { Introduction of new } \\
\text { concepts, frames of } \\
\text { reference or new paradigms } \\
\text { that help to reframe the } \\
\text { nature of specific problems } \\
\text { as well as their possible } \\
\text { solutions }\end{array}$ & Bekkers et al. (2011) & $\begin{array}{l}\text { The introduction of the } \\
\text { paradigm that, when } \\
\text { assessing a person's work } \\
\text { disability, insurance } \\
\text { physicians no longer } \\
\text { analyse what people cannot } \\
\text { do, but instead analyse what } \\
\text { they can still do, hence }\end{array}$ \\
\hline
\end{tabular}


When analysing the studies, each innovation identified was allocated to one of the abovementioned categories depending on its main goal (as identified in the publication studied). Although we have four main categories of innovation, we recognize that, in practice, these types are often intertwined creating hybrid forms. Nevertheless, this distinction serves as a helpful analytical tool to focus on the different forms of innovation

Occurrences of the different innovation categories identified are summarized in Table 2. Overall, our analysis shows that the dominant focus in the body of empirical knowledge on public sector innovation is on internal administrative, often technology-driven, processes.

TABLE 2 Types of public sector innovation

\begin{tabular}{lc}
\hline Innovation type & Number \\
\hline Process innovation & $105(47 \%)$ \\
Administrative process innovation & $89(40 \%)$ \\
Technological process innovation & $16(7 \%)$ \\
Product or service innovation & $49(22 \%)$ \\
Governance innovation & $29(13 \%)$ \\
Conceptual innovation & $4(2 \%)$ \\
Other & $35(16 \%)$ \\
\hline
\end{tabular}

Total N = $222(100 \%)$ - some studies included more than one type

By far the largest category consisted of administrative process innovations (a subset of process innovations). These are often driven by NPM-like reform ideas. For instance, Hansen (2011) analysed the relationship between leadership and the adoption of innovations associated with NPM among 262 Danish public managers. Innovations examined in this study included the outsourcing of initiatives by municipalities. The next largest category was product or service innovations (e.g. Pärna and Von Tunzelmann 2007). 
In the literature, much less attention has been paid to technological process innovations (a subset of process innovations, often related to e-government and redesign), governance innovations and conceptual innovations. An example of a governance innovation can be found in the study by Schoeman et al. (2012) where partnerships with private partners are put forward as a way to address societal challenges. This type of innovation is, however, receiving growing attention (65\% of all studies about governance innovations have been published since 2009). Finally, the category 'Other' included many topics. For instance, there were studies that focused to varying extents on the behavioural components of innovation such as on the public entrepreneur involved (Meijer 2014).

In summing up, we can say that the literature seems to lean towards intra-organizational process innovations, which are often closely related to two major reform movements in public administration, namely NPM and e-government. This suggests that other types, especially governance and conceptual but also inter-organizational innovations, have not been thoroughly investigated.

We now turn to the innovation goals encountered in our review.

\subsection{Innovation goals}

Table 3 shows, based on the studies analysed, the goals that public sector innovations sought to achieve. 
TABLE 3 Public sector innovation goals

\begin{tabular}{ll}
\hline Goals & Number \\
\hline Increasing effectiveness & $47(18 \%)$ \\
Increasing efficiency & $41(15 \%)$ \\
Tackling societal problems (e.g. addressing unemployment, overweight) & $28(10 \%)$ \\
Increasing customer satisfaction & $19(7 \%)$ \\
Involving citizens & $15(6 \%)$ \\
Involving private partners & $6(2 \%)$ \\
Other & $19(7 \%)$ \\
No goals mentioned & $92(35 \%)$ \\
\hline
\end{tabular}

Total $\mathrm{N}=267(100 \%)$ - some studies included more than one goal

The first striking observation is that $35 \%$ of the articles studied failed to mention any goals. One reason is that some studies did not focus on the goals of the innovation but, for instance, on the innovation process (e.g. Piening 2011).

The most often mentioned motivation for innovation (on 88 occasions) was improving performance, expressed in terms of effectiveness or efficiency. Studies that referred to this highlighted notions such as 'performing with less' (e.g. Kim and Lee 2009). This was especially the case in the UK healthcare sector (e.g. Turner et al. 2011) where government programmes stimulated hospitals to adopt management practices that often reflected NPM ideas. This goal was quite closely followed by goals related to participation and cooperation (on 68 occasions), for instance through involving citizens (e.g. Carter and Bélanger 2005).

These findings can be related to the two logics of action put forward by March and Olsen (1989) when trying to understand the functioning of the public sector: the logic of consequence and the logic of appropriateness. The logic of consequence looks at the effects of various alternatives while the logic of appropriateness relates actions to situations by means of rules organized into identities. The stressing of efficiency and effectiveness is often related to the logic of consequence (Weber et al. 2004). The logic of appropriateness typically refers to the legitimacy of government and the trust that citizens have that governments are able to deal with 
the problems they are concerned about, implying that citizens have to get more involved (e.g. Carter and Bélanger 2005). The appropriateness logic was present in $23 \%$ of the identified logics (whereas the consequence logic was present in 33\%), perhaps indicating that public innovations are not as strongly inspired by the private sector as many NPM reformers suggest (Hood 1991). That is, public sector innovation is not only about efficiency but also focused on acquiring trust and legitimacy (e.g. Bekkers et al. 2011).

Our next step was to identify the ways in which these goals were established.

\subsection{Antecedents in the innovation process}

In this section, we analyse antecedents that were identified as influential in the innovation process. Antecedents can, depending on their level and the specific context, be either a driver or a barrier. For instance, Borins (2001) mentioned the risk-averse public administration culture as a key aspect that hindered innovation. Conversely, other authors have identified a learning culture favouring innovation (e.g. Kumar and Rose 2010). As such, these two studies report distinct roles for organizational culture. As described in the 'Methodology' section, these antecedents have been categorized into drivers and barriers that relate to four main categories on four levels:

- environmental level: external context (e.g. political mandates)

- organizational level: aspects that include the structural and cultural features of an organization (e.g. organizational slack resources)

- innovation level: intrinsic attributes of an innovation (e.g. complexity of the innovation)

- individual/employee level: characteristics of individuals who innovate (e.g. empowerment)

Further, in Section 3.8 we explicitly distinguish between antecedents related to the innovation generation stage and those related to the adoption/diffusion stage of the innovation process. Innovation generation is 'a process that results in an outcome that is new to an organizational population' (Damanpour and Schneider 2009, p. 497). Innovation adoption is 'the voluntary 
and/or coercive process through which an organization passes from first knowledge of an innovation, to forming an attitude towards the innovation, to a decision to adopt or reject, to implementation of the new idea, and to confirmation of this decision' (Rogers 2003, p. 20). The diffusion of an innovation can be seen as 'a process in which an innovation is communicated through certain channels over time among the members of a social system' (Rogers 2003, p. 5).

In the literature, it is generally assumed that antecedents related to the diffusion and adoption stage are mainly centred on intrinsic innovation attributes (Rogers 2003), and that this makes this stage rather different from the innovation generation stage. Our question is whether the studies examined support this supposition.

In the following subsection, we will first describe the various antecedents encountered and then relate these antecedents to the various stages.

\section{Antecedents related to the environmental level}

Table 4 presents an overview of the antecedents related to the environmental level. This category covers those studies that analyse innovation activities that do not take place on the organizational, individual or innovation level. Very often, these antecedents were linked to the specific context in which an organization operated. This underlines the importance attached in the innovation literature to the idea that innovations are locally embedded and the result of co-evolution between different demands and pressures that stem from different but closely related (public, political and media) environments (Bekkers et al. 2011). 


\section{TABLE 4 Environmental antecedents}

\begin{tabular}{ll}
\hline Antecedent & Number \\
\hline Environmental pressures (media attention, political demands, public demands) & $22(29 \%)$ \\
Participation in networks and inter-organizational relationships & $21(27 \%)$ \\
Regulatory aspects & $12(16 \%)$ \\
Compatible agencies/organizations/states adopting the same innovation & $8(10 \%)$ \\
Competition with other organizations & $5(6 \%)$ \\
Other & $9(12 \%)$
\end{tabular}

Total N = $77(100 \%$

When considering the studies most often referred to in our sample, both DiMaggio and Powell (1991) and Borins (2000; 2001) are frequently cited. DiMaggio and Powell (1991) stress the notion of isomorphism or 'looking alike' as organizations in the same field become more similar. Conformity can be achieved through the adoption of specific rules and regulations through which, in an obligatory way, changes have to be implemented (coercive isomorphism), through the adoption of specific values and norms that are pushed forward by relevant peers and professional organizations (normative isomorphism) or through copying and mimicking (mimetic isomorphism).

Table 4 also shows that on eight occasions the number of compatible organizations adopting an innovation was addressed and this, at least partially, fits the notion of normative isomorphism. An example can be found in the work of Berry (1994) who noted that the greater the number of neighbouring state agencies that had already adopted strategic planning the greater the likelihood of innovation.

When further reflecting on antecedents related to the environmental level, we see that environmental antecedents such as media attention and political aspects are the most often mentioned (e.g. Borins 2000; 2001). Further, participation with other partners and the adoption of their norms is frequently noted (e.g. Mintrom and Vergari 1998), which could also reflect a form of mimetic isomorphism. 
Finally, regulatory aspects were also identified. In general, regulation is considered to hamper innovation (e.g. Johns et al. 2006). However, Rogers-Dillon (1999) argued that the prevailing wisdom, that limiting the federal role in welfare will free states to be more innovative, can be oversimplistic. In his study, the establishment of Florida's Family Transition Program (FTP), a pilot welfare-to-work programme, was the direct result of imposed federal requirements. Federal regulation, in this case, promoted innovation.

\section{Antecedents related the organizational level}

Many of the antecedents found in our review can be linked to the organizational context. On 44 occasions, Damanpour is cited. His work can be considered as a milestone on innovation in organizations and, in his meta-analysis on organizational innovations (Damanpour 1991), he highlighted how determinants such as slack resources and professionalism are positively connected to the adoption of innovations.

However, we would argue that, overall, our results do not show a clear citation network given that of the 369 included citations (insofar as CitNetExplorer depicts the citation networks for each study, see 'Methodology' section) only a minority refer to the most common sources (e.g. Damanpour 1991). Moreover, these multiple citations often come from the same author (Walker in the case of Damanpour).

Table 5 presents an overview of the organizational antecedents, which we defined as those aspects that reflect the structural and cultural features of an organization. 
TABLE 5 Organizational antecedents

\begin{tabular}{ll}
\hline Antecedent & Number \\
\hline Slack resources (time, money, ICT facilities) & $30(22 \%)$ \\
Leadership styles & $28(21 \%)$ \\
Degree of risk aversion/room for learning & $25(18 \%)$ \\
Incentives/rewards & $22(16 \%)$ \\
Conflicts & $10(8 \%)$ \\
Organizational structures & $10(8 \%)$ \\
Other & $9(7 \%)$ \\
\hline Total $\mathbf{N}=\mathbf{1 3 4}(\mathbf{1 0 0 \% )}$ & \\
\hline
\end{tabular}

First, the availability of organizational resources, especially in terms of organizational 'slack' (e.g. size, personnel, ICT facilities), is the most mentioned antecedent. For instance, Walker (2006) argues that the larger an organization is, the more 'slack' it has because it has more opportunities to cross-fertilize ideas as well as a larger range of relevant skills that can be exploited. Besides size, other often-discussed slack antecedents are organizational wealth and capacity (e.g. Bhatti et al. 2011) and the presence of talented employees in the organization (e.g. Maranto and Wolf 2013).

Second, studies have frequently examined the kind of leader required, such as leaders who 'have a vision' and are 'credible' (Gabris et al. 2001). The degree of risk aversion is also mentioned in various studies, including in the description of an administrative culture that hampers innovation (e.g. Borins 2001). Several publications also considered, given the importance of 'trial and error' in exploring new ideas, that a learning cultural environment was necessary for innovation to be promoted (e.g. Pärna and Von Tunzelmann 2007).

\section{Antecedents related to innovation characteristics}

In this section, we analyse the antecedents identified in our review that are related to the characteristics or key attributes of innovations (as perceived by prospective adopters). The main point of reference in these studies is an innovation's intrinsic characteristics as outlined in Rogers' Diffusion of Innovations Theory (2003). Five of the ten studies on adoption and 
diffusion referred to this (e.g. Carter and Bélanger 2005). Table 6 summarizes the characteristics identified in these studies.

\section{TABLE 6 Innovation characteristics}

\begin{tabular}{lc}
\hline Antecedent & Number \\
\hline Ease in use of innovation & $3(20 \%)$ \\
Relative advantage & $2(13 \%)$ \\
Compatibility & $2(13 \%)$ \\
Trialability & $2(13 \%)$ \\
Other (e.g. cost, trustworthiness, mouldability) & $6(41 \%)$ \\
\hline Total $\mathbf{N}=\mathbf{1 5}(\mathbf{1 0 0 \% )}$ & \\
\hline
\end{tabular}

Relative to the previous two dimensions, we found that there has been less empirical attention to the influence of characteristics of the innovation itself. Only a few studies, often when discussing the adoption and diffusion of innovations, mentioned them as being relevant. The innovation characteristics most often mentioned were an innovation's perceived ease-of-use (e.g. Carter and Bélanger 2005; Damanpour and Schneider 2009), its relative advantage, its trialability and its compatibility (e.g. Korteland and Bekkers 2008).

\section{Antecedents related to the individual level}

Table 7 shows the antecedents related to the individual levels that were identified in the reviewed studies. 


\section{TABLE 7 Individual antecedents}

\begin{tabular}{ll}
\hline Antecedent & Number \\
\hline Employee autonomy (empowerment) & $11(20 \%)$ \\
Organizational position (tenure, mobility) & $10(19 \%)$ \\
Job-related knowledge and skills (professionalism) & $8(15 \%)$ \\
Creativity (risk-taking, solving of problems) & $6(11 \%)$ \\
Demographic aspects (age, gender) & $6(11 \%)$ \\
Commitment/satisfaction with job & $5(9 \%)$ \\
Shared perspective and norms & $2(4 \%)$ \\
Innovation acceptance & $2(4 \%)$ \\
Other & $4(7 \%)$ \\
\hline
\end{tabular}

Total N = $54(100 \%)$

Key publications include Borins (2000) who highlights the importance of creative individual entrepreneurs who are able to break through a risk-averse administrative culture. This finding also aligns with the notion of empowered employees, who are frequently mentioned as an important source of successful innovation. In addition, we observe that job-related skills are highly valued (e.g. Bartlett and Dibben 2002). When combining these findings with results from the previous section (organization level antecedents), we see that agents have an import role in enabling innovation both on the organizational level (encompassing a strong focus on leadership) and the individual level (where there is a strong focus on innovative employees and their characteristics).

Having identified these various antecedents, it is also interesting to see whether they are present in both the generation and the diffusion/adoption stages of the innovation process.

\subsection{Antecedents related to the two stages of the innovation process}

This section looks at antecedents that are distinctly related to either the generation or the diffusion/adoption stage of the innovation process. Almost half of the studies identified (73; $40 \%$ ) dealt with diffusion and/or adoption, indicating that the diffusion and adoption process is rather well covered, although some authors disagree (for instance, Hartley 2005). 
Whereas the characteristics of an innovation were only considered in studies on the diffusion and adoption stages (e.g. Carter and Bélanger 2005), environmental, organizational and individual antecedents were seen as present in both the generation and the adoption stages. This overlap reflects that the adoption stage, to some extent, resembles the innovation generation stage. When looking at these common antecedents, similar patterns can be found. For instance, on the organizational level, we encountered a strong emphasis on the role of organizational slack or innovative leaders in both stages (e.g. Gabris et al. 2001; Walker 2006). Studies related to the individual level similarly include autonomy and skills in both stages (e.g. Bartlett and Dibben 2002). These findings suggest that the differences between these two stages are not as large as sometimes suggested if one looks at relevant drivers and barriers.

\subsection{Innovation outcomes}

Our last research question concerns the outcomes of innovation. In line with Kuipers et al. (2014), we define the outcomes of an innovation as the 'substantive results of the implementation of an innovation that can be intended or unintended and positive or negative'. The types of outcomes reported in the identified publications are summarized in Table 8.

TABLE 8 Outcomes of public sector innovation

\begin{tabular}{ll}
\hline Outcome & Number \\
\hline Effectiveness & $59(28 \%)$ \\
\multicolumn{1}{c}{ Increased effectiveness } & $56(27 \%)$ \\
$\quad$ Decreased effectiveness & $3(1 \%)$ \\
Increased efficiency & $21(10 \%)$ \\
Private partners involved & $13(6 \%)$ \\
Citizens involved & $11(5 \%)$ \\
Increased customer satisfaction & $10(5 \%)$ \\
Other (safety, fairness etc.) & $13(6 \%)$ \\
No outcomes mentioned & $84(40 \%)$
\end{tabular}

Total $\mathrm{N}=211(100 \%)$ - some studies included more than one outcome 
The first observation is that nearly half of the studies did not report outcomes $(84 ; 40 \%)$. Studies often mentioned some objective of the innovation in their introduction, such as improving effectiveness and efficiency, but failed to report whether these goals had been realized (e.g. Bartlett and Dibben 2002). In addition, many articles focused on the positive effects of innovations, and only a few considered specific innovation failures or reported a reduction in innovative activity (e.g. Piening 2011).

Where outcomes are reported, studies often record, in line with the goals, increased effectiveness and efficiency (e.g. Dias and Escoval 2013). Other outcomes, such as achieving citizen satisfaction, were less often reported. Only a few studies describe the pursuit of traditional public sector values such as safety and equality in schooling (Maranto and Wolf 2013). Studies that mentioned this kind of outcome (i.e. involving citizens) often also included performance features as relevant outcomes. For instance, the study by Pope et al. (2006) examined the way UK National Health Service (NHS) Treatment Centres reduced waiting lists for elective care. This outcome can be considered as both user-oriented (citizens get improved services) and efficiency focused (providing services with less effort).

From our review, we conclude that innovation is often considered as a value in itself, a finding in line with previous observations regarding the lack of reported goals when embarking on the innovation journey. This could imply that the process of generating or adopting an innovation is seen as sufficiently important in itself, which is also reflected in the processoriented outcomes that were mentioned in terms of involving private partners and increasing the role of citizens.

\subsection{Relationship between innovation types, outcomes and antecedents}

After having described the main antecedents and outcomes, we analyse whether some innovation types are more closely related to certain antecedents and outcomes than to others. Table 9 summarizes, for each innovation type, the frequency with which the different antecedents (environmental, organizational, innovation and individual) are mentioned. 
TABLE 9 Relationship between innovation types and antecedents in the public sector innovation process

\begin{tabular}{llllll}
\hline Innovation type & Environmental & Organizational & Innovation & Individual & Total \\
\hline Process innovation & $25 \%$ & $52 \%$ & $8 \%$ & $15 \%$ & $100 \%$ \\
Product or service innovation & $38 \%$ & $34 \%$ & $14 \%$ & $14 \%$ & $100 \%$ \\
Governance innovation & $55 \%$ & $39 \%$ & $3 \%$ & $3 \%$ & $100 \%$ \\
Conceptual innovation & $14 \%$ & $72 \%$ & $0 \%$ & $14 \%$ & $100 \%$ \\
Other & $24 \%$ & $49 \%$ & $0 \%$ & $27 \%$ & $100 \%$ \\
\hline
\end{tabular}

Two main conclusions can be drawn. First, we observe that organizational antecedents play the largest role in enabling all innovation types. This is in line with our previous findings in this section, reflecting a strong emphasis on internal-oriented organizational antecedents. Table 9 shows, for instance, that $52 \%$ of all process innovations can be linked to organizational antecedents, such as leadership (e.g. Damanpour and Schneider 2009). Second, governance innovations are frequently connected to environmental antecedents, including the resources of private partners. For instance, Schoeman et al. (2012) examine how private sector organizations contribute to public sector innovation, showing that innovative solutions can be fostered by public and private partners working together.

Related to this, we examine whether innovation types differ in the way they are connected with certain outcomes (see Table 10). The results show that all the innovation types described in our studies are most frequently reported in terms of the outcome of effectiveness. This is especially the case for process innovations. Further, Table 10 also highlights the failure of many of the studies to address outcomes. 
TABLE 10 Relationship between innovation types and outcomes of public sector innovation

\begin{tabular}{|c|c|c|c|c|c|c|c|c|}
\hline Innovation type & Effectiveness & Efficiency & $\begin{array}{l}\text { Involving } \\
\text { citizens }\end{array}$ & $\begin{array}{l}\text { Involving } \\
\text { private } \\
\text { partners }\end{array}$ & $\begin{array}{l}\text { Customer } \\
\text { satisfaction }\end{array}$ & Other & No outcome & Total \\
\hline $\begin{array}{l}\text { Process innovation } \\
\text { nat }\end{array}$ & $33 \%$ & $12 \%$ & $4 \%$ & $6 \%$ & $3 \%$ & $6 \%$ & $36 \%$ & $100 \%$ \\
\hline $\begin{array}{l}\text { Product or service } \\
\text { innovation }\end{array}$ & $26 \%$ & $8 \%$ & $4 \%$ & $8 \%$ & $4 \%$ & $9 \%$ & $41 \%$ & $100 \%$ \\
\hline Governance innovation & $17 \%$ & $7 \%$ & $15 \%$ & $17 \%$ & $4 \%$ & $17 \%$ & $23 \%$ & $100 \%$ \\
\hline Conceptual innovation & $14 \%$ & $0 \%$ & $14 \%$ & $14 \%$ & $14 \%$ & $14 \%$ & $30 \%$ & $100 \%$ \\
\hline Other & $21 \%$ & $15 \%$ & $0 \%$ & $0 \%$ & $0 \%$ & $3 \%$ & $61 \%$ & $100 \%$ \\
\hline
\end{tabular}

\section{Conclusions}

The goal of this article was to present a systematic review of the literature on innovation in the public sector. In so doing, we aimed to take stock of the available empirical knowledge by integrating the insights developed elsewhere. Further, we aimed to develop a research agenda for the future, thereby contributing to the further institutionalization of the innovation theme in public administration.

More than half of the studies we found used qualitative methods, such as interviews or focus groups. Quantitative studies, and especially mixed-method studies, were less common. We also found that innovation was often weakly conceptualized, while the main body of knowledge is focused on internal-driven, often administrative, process innovations. Moreover, outcomes are often not reported, limiting what we know about the effects of innovation efforts.

The main limitations of such a review are bias in the selection of publications included and inaccuracy in data extraction. To help to ensure that the process of selection was unbiased, we developed a research protocol in advance that defined the research questions. Similarly, as described in Section 2, a multistage process was utilized that documented the reasons for inclusion/exclusion at every step. Further, since our focus was on empirical research, we excluded articles that were focused on providing theoretical statements. 
Figure 2 presents the unifying heuristic framework that we derived from our synthesis of empirical findings. This framework is intended as a guide when considering the various aspects of a complex situation and their many interactions, and should not be viewed as a prescriptive formula. As such, the components of this framework do not represent a comprehensive list of public sector innovations, but reflect only those areas on which research has been undertaken and findings published. For instance, we found that little attention had been paid to innovation outcomes such as legitimacy, and also that conceptual innovations had scarcely been researched.

FIGURE 2 Heuristic framework of public sector innovation

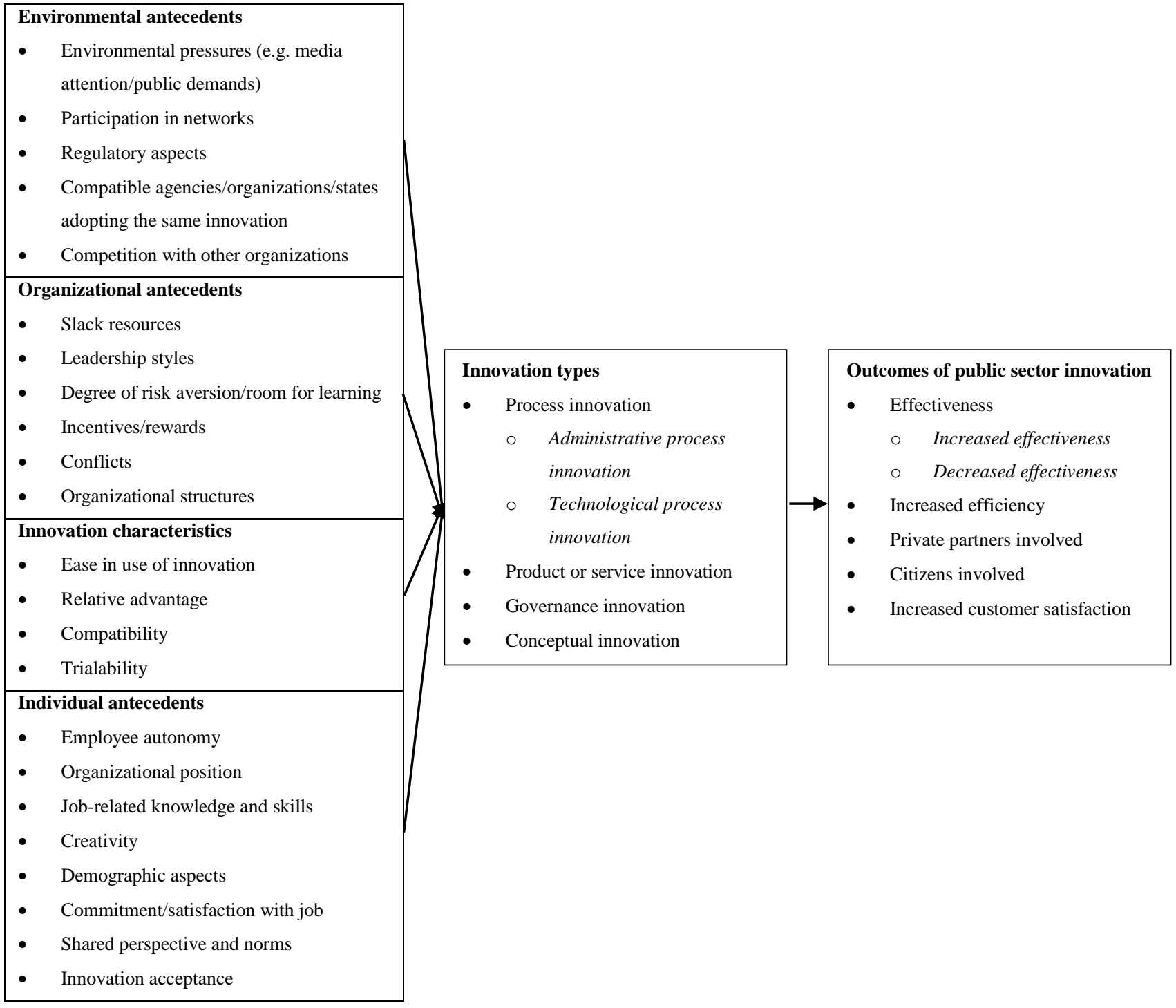


A number of important conclusions can be drawn from the systematic review of the literature.

First, we found a lack of a clear theoretical underpinning in the studies reviewed. We saw that only a few studies referred to existing theories such as those of Rogers (2003) on the diffusion of innovations and of Damanpour (1991) on innovations within organizations. Moreover, only a small group of authors are regularly cited. Our review also indicates that the empirical research to date has been largely unsuccessful in identifying and explaining what occurs after innovations are initiated, and this is largely because the emphasis primarily lies on the innovation process or the adoption of an innovation. By establishing links with existing theories, it could be possible to develop better explanations of the actual impacts of innovations, thereby answering the question: did these innovations really matter and really make a difference? Most of the empirical studies on innovation examined failed to address this issue.

Second, what typically is the 'publicness' (Bozeman and Bretschneider 1994) of public sector innovations? We found environmental antecedents that appeared to be typical of public sector innovation, such as political and public demands (e.g. Borins 2000). However, it was not always possible to disentangle the importance of these antecedents relative to others not specifically related to the public sector. Here, the concept of 'publicness' might be a useful addition (Bozeman and Bretschneider 1994) as this can make the distinction clear between public and private sector innovations. This can be defined as 'a characteristic of an organization which reflects the extent the organization is influenced by political authority' (Bozeman and Bretschneider 1994, p. 197). Here, an important challenge is to understand how the role of political authority influences the shaping and outcomes of public sector innovations as well as the antecedents that influence the legitimacy of political authority. The latter also relates to the previous remark that, when discussing the influence of the logics of consequence and of appropriateness in Section 3.6, an important driver for public sector innovation is the desire to secure the trust in and the legitimacy of government.

Third, we found that antecedents were often addressed independently, ignoring possible connections between them. Only a few studies explicitly looked for combined effects, for 
instance by combining environmental and organizational antecedents (e.g. Borins 2000). Further, when analysing combinations of antecedents in future research, it would be particularly interesting to analyse the process dynamic that occurs between particular antecedents. Which antecedents are first employed, and why? For instance, do organizations start innovations because of peer pressure (behaviour of similar organizations) and then adapt their organizational structure?

\section{Future research agenda}

Having completed this review, what do our findings imply about the current status of public sector innovation and where should innovation research go from here? Based on the results of the review, we now outline possible methodological, theoretical and empirical avenues.

First, we suggest that the next generation of research on public sector innovations should employ multi-method studies that cross countries or sectors. More than half of the studies we found used qualitative methods, such as interviews. Quantitative studies were less common. Further, there were almost no cross-national studies with many in the form of single country (often the US or the UK) qualitative case studies. While this is understandable given the importance of the local context when studying innovation, comparative studies that cut across countries or sectors could show to what extent antecedents are generalizable. Moreover, using a wider range of methods (such as participant observations and experiments) in public administration research could increase understanding since all methods have strengths and weaknesses. For instance, we do not know the impact of structural organizational characteristics, such as size, compared to that of organizational antecedents such as leadership. In order to determine the strength of these possible causal linkages, experiments are required.

A second suggestion is theoretical in nature, and relates to the fact that we found many studies that did not link to existing theories. A number of avenues for linking public innovation research to existing theories could be explored. Research on the diffusion of innovation could provide a theoretical underpinning for predicting how patterns of innovation are developed and adopted by organizations. This might also help in developing arguments for how innovations are 
diffused within a certain population of organizations. Neo-institutional theory, which is concerned with the spread of organizational practices within groups of similar organizations (DiMaggio and Powell 1991), could be further explored in investigating the relative influence of environmental antecedents on innovation. Central to neo-institutional theory is the assumption that the pursuit of legitimacy leads organizations within a field to adopt a limited range of structures, strategies and process, and hence become isomorphistic within that organizational field. How and under what circumstances might this be the case for public sector innovations?

Finally, the published findings do not enable us to address differences in national culture and governance traditions. There is therefore a gap in our understanding of innovation processes across different cultural contexts. This is largely a consequence of the strong UK/USA focus in the studies available for our analysis and the lack of cross-country analyses. Hence, future research could usefully link different types of governance and state traditions to the extent that innovativeness is seen in the public sector as well as to the antecedents that shape public sector innovations and their outcomes (Pollitt and Bouckaert 2011).

Concluding, this article has reported on a systematic review of the literature on innovations in the public sector. Public sector innovation is an important issue on the agenda of policymakers and academics when discussing the role of government in dealing with 'wicked problems' in an age of austerity. It is often considered as a 'magic concept' (Pollitt and Hupe 2011). This study is a first step in looking beyond the rhetoric of many public sector innovations and reform programmes. It has shown how little we know about public sector innovation and suggests the kind of empirical and theoretical knowledge and research that is needed to understand and criticize the innovation journeys on which many governments have embarked.

\section{Acknowledgements}

In order to conduct the systematic review of the literature, we among else consulted a number of experts to help us find eligible studies on public sector innovation. We thank these experts, specifically Prof. Sandford Borins from the University of Toronto-Scarborough, Prof. Richard Walker from the City University of Hong Kong, and Prof. Stephen Osborne from the University 
of Edinburgh. We would furthermore like to thank the four anonymous referees who offered valuable critiques and provided us with constructive suggestions, thereby improving the article substantially.

\section{Funding}

This work was supported by the European Union Seventh Framework Programme [320090] (Project Learning from Innovation in Public Sector Environments, LIPSE), Socio-economic Sciences and Humanities. LIPSE is a research program under the European Commission's 7th Framework Programme as a Small or Medium-Scale Focused Research Project (2011-2014). The project focuses on studying social innovations in the public sector (www.lipse.org).

\section{References}

*References included in the systematic review and cited in this article. Note that not all publications included in our review have been cited.

*Bartlett, D. and P. Dibben. 2002. 'Public Sector Innovation and Entrepreneurship: Case Studies from Local Government', Local Government Studies, 28, 4, 107-121.

Bason, C. 2010. Leading Public Sector Innovation: Co-creating for a Better Society. Bristol: Policy Press.

Bekkers, V.J.J.M., J. Edelenbos and B. Steijn. 2011. Innovation in the Public Sector. Linking Capacity and Leadership. New York: Palgrave Macmillan.

Bekkers, V.J.J.M. and V.M.F. Homburg (eds). 2005. The Information Ecology of E-Government: E-Government as Institutional and Technological Innovation in Public Administration. Amsterdam: IOS Press.

*Berry, F.S. 1994. 'Innovation in Public Management: The Adoption of Strategic Planning', Public Administration Review, 54, 5, 322-330.

*Bhatti, Y., A.L. Olsen and L.H. Pedersen. 2011. 'Administrative Professionals and the Diffusion of Innovations: The Case of Citizen Service Centres', Public Administration, 89, 2, 577-594. 
*Borins, S. 2000. 'Loose Cannons and Rule Breakers, or Enterprising Leaders? Some Evidence about Innovative Public Managers', Public Administration Review, 60, 498-507.

*Borins, S. 2001. 'Encouraging innovation in the Public Sector', Journal of Intellectual Capital, 2, 3, 310-319.

Bozeman, B. and S. Bretschneider. 1994. 'The "Publicness Puzzle" in Organization Theory: A Test of Alternative Explanations of Differences between Public and Private Organizations', Journal of Public Administration Research and Theory, 4, 2, 197-224.

*Brown, L. 2010. 'Balancing Risk and Innovation to Improve Social Work Practice', British Journal of Social Work, 40, 4, 1211-1228.

*Carter, L. and F. Bélanger. 2005. 'The Utilization of E-government Services: Citizen Trust, Innovation and Acceptance Antecedents', Information Systems Journal, 15, 1, 5-25.

Chesbrough, H.W. 2003. Open Innovation: The New Imperative for Creating and Profiting from Technology. Boston: Harvard Business Press.

Cooper, H. 2010. Research Synthesis and Meta-Analysis: A Step-by-Step Approach, 4th edn. Thousand Oaks, CA: Sage.

Damanpour, F. 1991. 'Organizational Innovation: A Meta-Analysis of Effects of Determinants and Moderators', Academy of Management Journal, 34, 3, 555-590.

*Damanpour, F. and M. Schneider. 2009. 'Characteristics of Innovation and Innovation Adoption in Public Organizations: Assessing the Role of Managers', Journal of Public Administration Research and Theory, 19, 3, 495-522.

*Dias, C. and A. Escoval. 2013. 'Improvement of Hospital Performance through Innovation: Toward the Value of Hospital Care', The Health Care Manager, 32, 2, 129-140.

DiMaggio, P.J. and W.W. Powell. 1991. The New Institutionalism in Organizational Analysis. Chicago, IL: University of Chicago Press.

Edquist, C., L. Hommen and M.D. McKelvey. 2001. Innovation and Employment: Process versus Product Innovation. Cheltenham: Edward Elgar Publishing.

Fagerberg, J., D.C. Mowery and R.R. Nelson (eds). 2005. The Oxford Handbook of Innovation. Oxford: Oxford University Press. 
Flynn, N. 2007. Public Sector Management, 5th edn. Thousand Oaks, CA: Sage.

*Gabris, G.T., R.T. Golembiewski and D.M. Ihrke. 2001. 'Leadership Credibility, Board Relations, and Administrative Innovation at the Local Government Level', Journal of Public Administration Research and Theory, 1, 1, 89-108.

Greenhalgh, T., G. Robert, F. Macfarlane, P. Bate and O. Kyriakidou. 2004. 'Diffusion of Innovations in Service Organizations: Systematic Review and Recommendations', Milbank Quarterly, 82, 4, 581-629.

*Hansen, M.B. 2011. 'Antecedents of Organizational Innovation: The Diffusion of New Public Management into Danish Local Government', Public Administration, 89, 2, 285-306.

Hartley, J. 2005. 'Innovation in Governance and Public Services: Past and Present', Public Money \& Management, 25, 1, 27-34.

Hood, C. 1991. 'A Public Management for All Seasons?', Public Administration, 69, 1, 3-19.

*Johns, C.M., P.L. O’Reilly and G.J. Inwood. 2006. 'Intergovernmental Innovation and the Administrative State in Canada', Governance, 19, 4, 627-649.

*Kim, S.E. and J.W. Lee. 2009. 'The Impact of Management Capacity on Government Innovation in Korea: An Empirical Study', International Public Management Journal, 12, 3, 345-369.

*Korteland, E. and V.J.J.M. Bekkers. 2008. 'The Diffusion of Electronic Service Delivery Innovations in Dutch E-policing: The Case of Digital Warning Systems', Public Management Review, 10, 1, 71-88.

Kuipers, B.S., M. Higgs, W. Kickert, L.G. Tummers, J. Grandia and J. Van der Voet. 2014. 'The Management of Change in Public Organizations: A Literature Review', Public Administration, 92, 1, 1-20.

*Kumar, N. and R.C. Rose. 2012. 'The Impact of Knowledge Sharing and Islamic Work Ethic on Innovation Capability', Cross Cultural Management: An International Journal, 19, 2, 142165.

Lowndes, V. and L. Pratchett. 2012. 'Local Governance under the Coalition Government: Austerity, Localism and the 'Big Society”, Local Government Studies, 38, 1, 21-40. 
*Maranto, R. and P.J. Wolf. 2013. 'Cops, Teachers, and the Art of the Impossible: Explaining the Lack of Diffusion of Innovations that Make Impossible Jobs Possible', Public Administration Review, 73, 2, 230-240.

March, J.G. and J.P. Olsen. 1989. Rediscovering Institutions: The Organizational Basis of Politics. New York: Free Press.

Meeus, M.T.H. and C. Edquist. 2006. ‘Introduction to Part I: Product and Process Innovation', in Hage, J. and M.T.H. Meeus (eds), Innovation, Science, and Institutional Change. Oxford: Oxford University Press, pp. 23-37.

*Meijer, A.J. 2014. 'From Hero-Innovators to Distributed Heroism: An In-Depth Analysis of the Role of Individuals in Public Sector Innovation', Public Management Review, 16, 2, 199216.

*Mintrom, M. and S. Vergari. 1998. 'Policy Networks and Innovation Diffusion: The Case of State Education Reforms', The Journal of Politics, 60, 1, 26-148.

Moher, D., A. Liberati, J. Tetzlaff and D.G. Altman. 2009. 'Preferred Reporting Items for Systematic Reviews and Meta-Analyses: The PRISMA Statement', Annals of Internal Medicine, 151, 4, 264-269.

Moore, M. and J. Hartley. 2008. 'Innovations in Governance', Public Management Review, 10, 1, 3-20.

*Nählinder, J. 2010. 'Where are all the Female Innovators?: Nurses as Innovators in a Public Sector Innovation Project', Journal of Technology Management \& Innovation, 5, 1, 13-29.

Osborne, D. and T. Gaebler. 1992. Reinventing Government: How the Entrepreneurial Spirit is Transforming the Public Sector. Reading, MA: Addison-Wesley.

Osborne, S.P. and L. Brown. 2011. 'Innovation, Public Policy and Public Services Delivery in the UK. The Word that Would Be King?', Public Administration, 89, 4, 1335-1350.

Osborne, S.P. and L. Brown (eds). 2013. Handbook of Innovation in Public Services. Northampton, MA: Edward Elgar Publishing.

*Pärna, O. and N. Von Tunzelmann. 2007. 'Innovation in the Public Sector: Key Features Influencing the Development and Implementation of Technologically Innovative Public 
Sector Services in the UK, Denmark, Finland and Estonia', Information Polity, 12, 3, 109125.

Perks, H. and D. Roberts. 2013. 'A Review of Longitudinal Research in the Product Innovation Field, with Discussion of Utility and Conduct of Sequence Analysis', Journal of Product Innovation Management, 30, 6, 1099-1111.

*Piening, E.P. 2011. 'Insights into the Process Dynamics of Innovation Implementation: The Case of Public Hospitals in Germany', Public Management Review, 13, 1, 127-157.

Pollitt, C. and G. Bouckaert. 2011. Public Management Reform: A Comparative Analysis -New Public Management, Governance, and the Neo-Weberian State, 3rd edn. Oxford: Oxford University Press.

Pollitt, C. and P. Hupe. 2011. 'Talking about Government: The Role of Magic Concepts', Public Management Review, 13, 5, 641-658.

*Pope, C., G. Robert, P. Bate, A. Le May and J. Gabbay. 2006. 'Lost in Translation: A Multi-level Case Study of the Metamorphosis of Meanings and Action in Public Sector Organizational Innovation', Public Administration, 84, 1, 59-79.

Rhodes, R.A.W. 1996. 'The New Governance: Governing without Government', Political Studies, $44,4,652-667$.

Rogers, E.M. 2003. Diffusion of Innovations, 5th edn. New York: Free Press.

*Rogers-Dillon, R.H. 1999. 'Federal Constraints and State Innovation: Lessons from Florida's Family Transition Program', Journal of Policy Analysis and Management, 18, 2, 327-332.

*Salge, T.O. and A. Vera. 2012. 'Benefiting from Public Sector Innovation: The Moderating Role of Customer and Learning Orientation', Public Administration Review, 72, 4, 550-559.

*Schoeman, M., D. Baxter, K. Goffin and P. Micheli. 2012. 'Commercialization Partnerships as an Enabler of UK Public Sector Innovation: The Perfect Match?', Public Money \& Management, 32, 6, 425-432.

Schumpeter, J.A. 1942. Capitalism, Socialism and Democracy. New York: Harper.

Sørensen, E. and J. Torfing. 2011. 'Enhancing Collaborative Innovation in the Public Sector', Administration \& Society, 43, 8, 842-868. 
Tummers, L.G., V.J.J.M. Bekkers, E. Vink and M. Musheno (forthcoming). 'Coping during Public Service Delivery: A Conceptualization and Systematic Review of the Literature', Journal of Public Administration Research and Theory.

*Turner, S., P. Allen, W. Bartlett and V. Pérotin. 2011. 'Innovation and the English National Health Service: A Qualitative Study of the Independent Sector Treatment Centre Programme', Social Science \& Medicine, 73, 4, 522-529.

Van Eck, N.J. and L. Waltman. 2014. 'CitNetExplorer: A New Software Tool for Analyzing and Visualizing Citation Networks', Journal of Informetrics, 8, 4, 802-823.

*Walker, R.M. 2006. 'Innovation Type and Diffusion: An Empirical Analysis of Local Government', Public Administration, 84, 2, 311-335.

Walker, R.M. 2014. 'Internal and External Antecedents of Process Innovation: A Review and Extension', Public Management Review, 16, 1, 21-44.

Weber, J.M., S. Kopelman and D.M. Messick. 2004. 'A Conceptual Review of Decision Making in Social Dilemmas: Applying a Logic of Appropriateness', Personality and Social Psychology Review, 8, 3, 281-307. 


\section{Appendix PRISMA checklist (based on Moher et al. 2009)}

Note: some checks are not applicable as they are meant for a meta-analysis, not a systematic review.

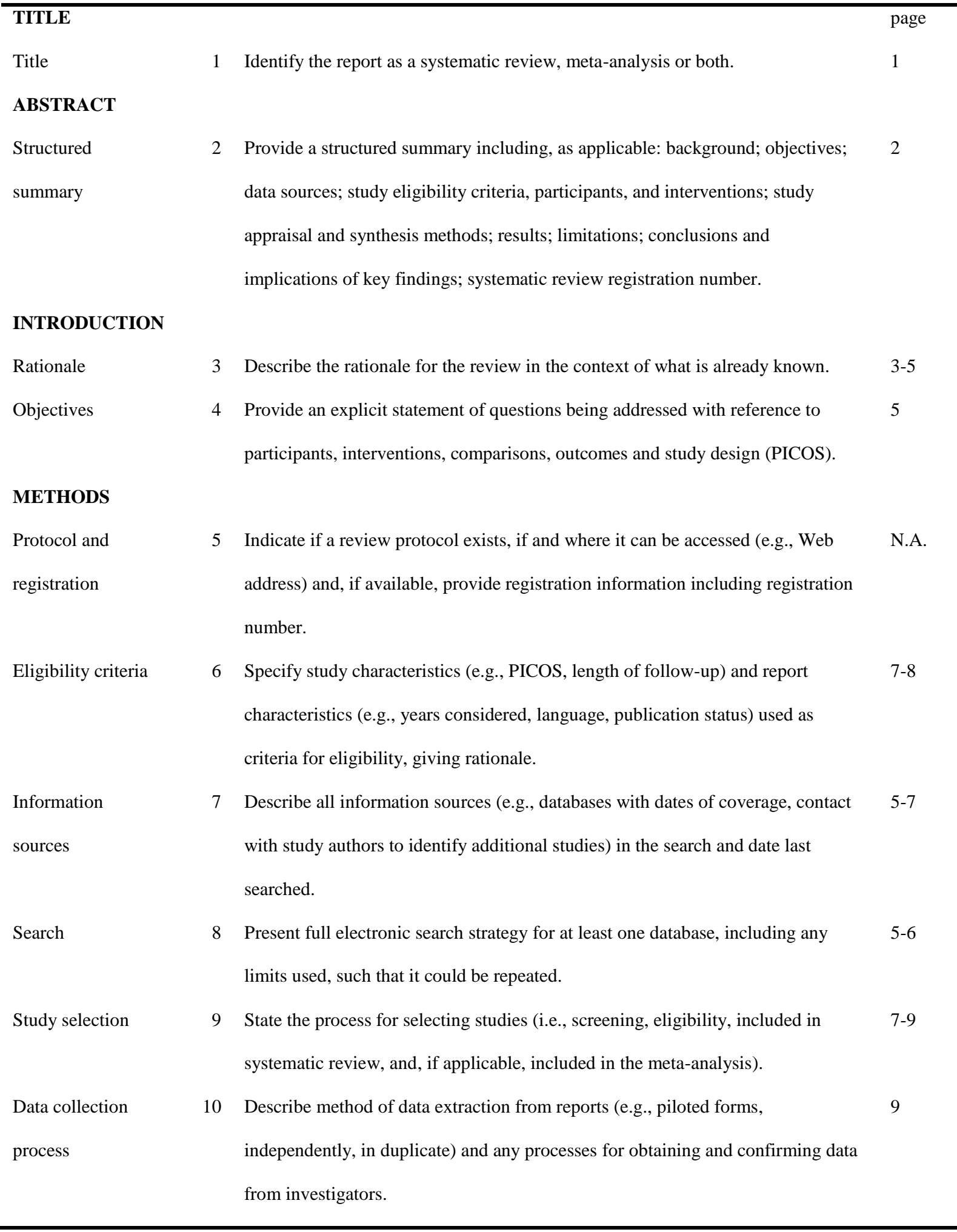




\begin{tabular}{|c|c|c|c|}
\hline Data items & 11 & $\begin{array}{l}\text { List and define all variables for which data were sought (e.g., PICOS, funding } \\
\text { sources) and any assumptions and simplifications made. }\end{array}$ & $5-7$ \\
\hline $\begin{array}{l}\text { Risk of bias in } \\
\text { individual studies }\end{array}$ & 12 & $\begin{array}{l}\text { Describe methods used for assessing risk of bias in individual studies (including } \\
\text { specification of whether this was done at the study or outcome level), and how } \\
\text { this information is to be used in any data synthesis. }\end{array}$ & N.A. \\
\hline Summary measures & 13 & State the principal summary measures (e.g., risk ratio, difference in means). & N.A. \\
\hline Synthesis of results & 14 & $\begin{array}{l}\text { Describe the methods for handling data and combining results of studies, if done, } \\
\text { including measures of consistency (e.g., I) for each meta-analysis. }\end{array}$ & N.A. \\
\hline $\begin{array}{l}\text { Risk of bias across } \\
\text { studies }\end{array}$ & 15 & $\begin{array}{l}\text { Specify any assessment of risk of bias that may affect the cumulative evidence } \\
\text { (e.g., publication bias, selective reporting within studies). }\end{array}$ & 7 \\
\hline $\begin{array}{l}\text { Additional } \\
\text { analyses }\end{array}$ & 16 & $\begin{array}{l}\text { Describe methods of additional analyses (e.g., sensitivity or subgroup analyses, } \\
\text { meta-regression), if done, indicating which were pre-specified. }\end{array}$ & N.A. \\
\hline RESULTS & & & \\
\hline Study selection & 17 & $\begin{array}{l}\text { Give numbers of studies screened, assessed for eligibility and included in the } \\
\text { review, with reasons for exclusions at each stage, ideally with a flow diagram. }\end{array}$ & 8 \\
\hline $\begin{array}{l}\text { Study } \\
\text { characteristics }\end{array}$ & 18 & $\begin{array}{l}\text { For each study, present characteristics for which data were extracted (e.g., study } \\
\text { size, PICOS, follow-up period) and provide the citations. }\end{array}$ & 9 \\
\hline $\begin{array}{l}\text { Risk of bias within } \\
\text { studies }\end{array}$ & 19 & $\begin{array}{l}\text { Present data on risk of bias for each study and, if available, any outcome level } \\
\text { assessment (see item 12). }\end{array}$ & N.A. \\
\hline $\begin{array}{l}\text { Results of } \\
\text { individual studies }\end{array}$ & 20 & $\begin{array}{l}\text { For all outcomes considered (benefits or harms), present, for each study: (a) } \\
\text { simple summary data for each intervention group (b) effect estimates and } \\
\text { confidence intervals, ideally with a forest plot. }\end{array}$ & N.A. \\
\hline Synthesis of results & 21 & $\begin{array}{l}\text { Present the main results of the review. If meta-analyses are done, include for } \\
\text { each, confidence intervals and measures of consistency }\end{array}$ & $10-23$ \\
\hline $\begin{array}{l}\text { Risk of bias across } \\
\text { studies }\end{array}$ & 22 & Present results of any assessment of risk of bias across studies (see Item 15). & N.A. \\
\hline Additional analysis & 23 & $\begin{array}{l}\text { Give results of additional analyses, if done (e.g., sensitivity or subgroup analyses, } \\
\text { meta-regression [see Item 16]). }\end{array}$ & N.A. \\
\hline DISCUSSION & & & \\
\hline $\begin{array}{l}\text { Summary of } \\
\text { evidence }\end{array}$ & 24 & $\begin{array}{l}\text { Summarize the main findings including the strength of evidence for each main } \\
\text { outcome; consider their relevance to key groups (e.g., healthcare providers, users, } \\
\text { and policy makers). }\end{array}$ & $10-22$ \\
\hline Limitations & 25 & $\begin{array}{l}\text { Discuss limitations at study and outcome level (e.g., risk of bias), and at review- } \\
\text { level (e.g., incomplete retrieval of identified research, reporting bias). }\end{array}$ & 23 \\
\hline
\end{tabular}


implications for future research.

\section{FUNDING}

Funding

27 Describe sources of funding for the systematic review and other support (e.g., See supply of data); role of funders for the systematic review. funding 